\title{
Value-Driven Strategic Sourcing Based on Service-Dominant Logic
}

\author{
Laleh Rafati, Geert Poels \\ Center for Service Intelligence \\ Faculty of Economics and Business Administration, Ghent University, \\ Tweekerkenstraat 2, 9000 Gent, Belgium \\ \{laleh.rafati, geert.poels\}@UGent.be
}

\begin{abstract}
Currently, procurement is approached as a tactical process focused on spend management. The aim of this process is the identification of cost savings. A new paradigm of procurement is emerging that recognizes procurement as a value creation practice. This paradigm, referred to as value-driven strategic sourcing, lacks instruments for implementation. This paper presents a new conceptual modeling approach for exploring and evaluating sourcing alternatives that is based on a systemic view of value co-creation. Our approach, called C.A.R.S (which stands for Capability, Actor, Resource, and Service), is the result of a Design Science Research project. The paper presents the underlying conceptualization of C.A.R.S, which was constructed through a mapping between service ecosystem concepts grounded in Service-Dominant Logic and the Viable System Approach and strategic sourcing concepts derived from the Resource-Based View Theory of competitive advantage, the Dynamic Capability Theory, and the Relational View Theory of cooperation and competition. Apart from presenting the theoretical foundation of C.A.R.S, we also demonstrate by means of a case study of sustainable procurement in a global materials technology company how a model-based approach based on C.A.R.S helps implementing value-driven strategic sourcing. The case-study provides a proof-of-concept of the potential utility of our approach as it addresses specific problems with the company's current procurement practices.
\end{abstract}

Keywords: Service-Dominant Logic, Viable System Approach, strategic sourcing, capability sourcing, value co-creation, value-driven management.

\section{Introduction}

The increasing importance of supply chains and their management has resulted in an evolving view of procurement from a buying function to a key element in a strategic approach to supply chain management (Chen et al 2004), (Anderson and Rask 2013). The strategic role of procurement has been recognized through its sub-process of strategic sourcing as described in (Van Weele 2009), (Cox 2015). Fig. 1 depicts the starting of procurement with spend analysis and its ending with payment. Two distinct phases in procurement can be distinguished. The first phase is sourcing which involves the source-to-contract (S2C) process with three sequential activities: 1) spend analysis as the activity which collects and analyzes spend data and identifies potential cost reduction opportunities; 2) the activity of strategic sourcing proper in which the best go-to-market sourcing strategy is decided on, to be followed by supplier evaluation and selection taking into account the strategic goals of the company; and 3) contract management which is the activity responsible for tracking and controlling the legal and formal agreements with suppliers in order to fully exploit contract arrangements. The second phase is purchasing which involves the purchaseto-pay ( $\mathrm{P} 2 \mathrm{C}$ ) process with another three activities: 1) the requisition of the purchase; 2) purchase the placing of the purchase order and the receiving of its confirmation; 3) notifying the delivery and effectuating the payment. 
Procurement

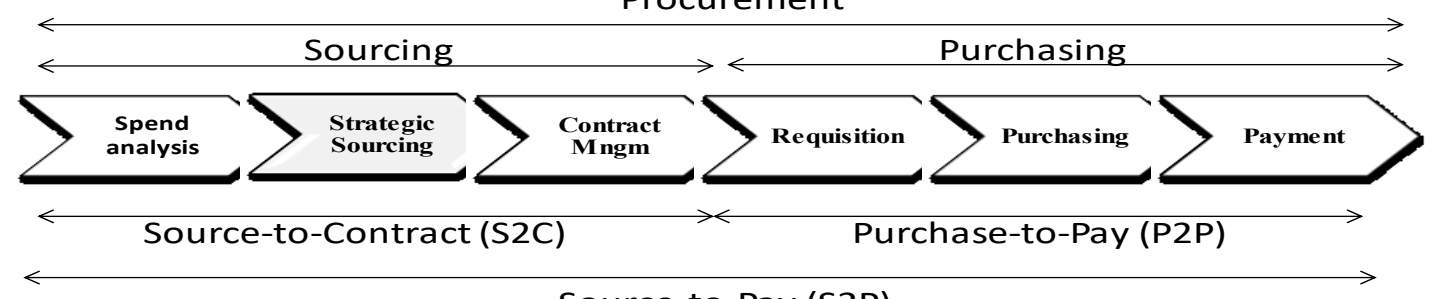

Source-to-Pay (S2P)

Fig. 1. Procurement process

Approaches in use for strategic sourcing such as the purchasing chessboard approach (Schuh et al. 2009) put strong emphasis on achieving cost savings targets by means of spend analysis techniques and market positioning techniques (Kraljic 1983), (Cox 2001). A shortcoming of these approaches is that they implement strategic sourcing as a tactical spend management process instead of a strategic important process for the organization (Cox 2015). These approaches also assume that strategic sourcing is conducted on a project per project basis rather than as a continuous process. Typically, the strategic sourcing project involves segmenting purchase categories by the size of spend (e.g., using the spend cube analysis technique) and then creating 'category project teams' responsible for delivering cost savings within their assigned purchase category.

The unit of analysis in existing approaches to strategic sourcing is the individual firm and the focus is on the firm's transactions in supply management to achieve cost-saving targets. According to (Cox and Ireland 2015), organizations have to understand that strategic sourcing should be implemented as an end-to-end process, which enables to manage the flow of value within the company and between the company and its suppliers, customers, complementors and competitors. Cox (2015) introduced a new (strategic) way of thinking for strategic sourcing as value-driven management that focuses on relationships (rather than transactions) in supply management to achieve value-driven targets. According to this strategic thinking, sourcing is a process that is implemented cross-functionally and that continuously evaluates trade-offs of value for money.

The strategic thinking of Cox recognizes that organizations are rarely interested in purchase items because of what they cost. Organizations need to source items in order to achieve their strategic goals commercially and operationally. To meet these goals, they need to understand the value embedded within the items of their purchase categories, and not just their price or cost of ownership. In other words, strategic sourcing requires an understanding of the entire value net. The value net comprises all interdependencies and relationships for joint value creation (i.e., 'cocreation') among the actors in a firm's network, enabling firms to compete and cooperate at the same time (Brandenburger and Nalebuff 2011).

Although the need for acquiring a deep understanding of an organization's value creation relationships is fairly well recognized, managers are still challenged by many barriers to its implementation (Kocabasoglu and Suresh 2006). The main challenge is the lack of practical instruments (i.e., tools and techniques) to implement the value-driven management approach to strategic sourcing (Cox 2015). Our research aims at addressing this challenge. After conducting a literature review and analysis of value-driven management in strategic sourcing, we specified the following requirements to help realizing value-driven strategic sourcing (Rafati and Poels 2016): Creating a holistic view on the firm's value network (Req.1), emphasizing value co-creation 
(Req.2) by considering inter-firm interactions (Req.3), to support an organization in exploring strategic sourcing alternatives (Req.4) in order to better achieve its strategic goals.

Our approach to meet these requirements is conceptual modeling (Thalheim 2012). The field of Conceptual Modeling can contribute to strategic sourcing decision-making in different ways. Based on Osterwalder and Pigneur (2013), we argue that a conceptual model can support the identification, formalization, and visualization of the concepts that are relevant for value-driven strategic sourcing. Furthermore, conceptual modeling can support the design of model-based techniques for generating and assessing strategic sourcing alternatives. Finally, a conceptual model can be the basis for developing computer-aided design tools, which assist in automating the process of designing strategic sourcing alternatives.

To build conceptual models for describing, exploring, and evaluating possible alternatives following value-driven strategic sourcing thinking, a new domain-specific modeling language for strategic sourcing is needed. Hence, in (Rafati and Poels 2016) we defined two research objectives:

- The design of a systemic view of strategic sourcing that focuses on the value co-creation relations that are embedded in the interactions between firms, like resource integration, capability configuration and service exchanges. (referring to Req.1, Req.2, and Req.3)

- The design of a conceptual modeling language that is based on the systemic view of strategic sourcing, to be used for exploring alternatives in strategic sourcing such that value-driven targets can be achieved. (referring to Req.4)

A systemic view on strategic sourcing recognizes that a firm is part of a value net of organizations that are linked through inter-firm relationships which aim at value co-creation. In this paper, we argue that such systemic view can be designed by taking a service ecosystem perspective of an organization. We introduce our proposed language called C.A.R.S (Capability - Actor - Resource - Service) and explain how we designed it through a mapping between service ecosystem concepts grounded in Service-Dominant Logic (Lusch and Vargo 2006), (service) systems thinking (Spohrer et al. 2010) and the Viable System Approach (Polese and Di Nauta 2013) and strategic sourcing concepts derived from the Resource-Based View Theory (Barney 1991) of competitive advantage, the Dynamic Capability Theory (Helfat et al. 2009), and the Relational View Theory (Dyer and Singh 1998) of cooperation and competition. We also demonstrate by means of a case study of sustainable procurement in a global materials technology company how a model-based approach based on C.A.R.S helps implementing value-driven strategic sourcing.

As the intended solution to our research problem is the creation of a new artefact, we engaged in Design Science Research (DSR) (Hevner et al. 2004). Section 2 describes our research process which followed the DSR methodology proposed in (Peffers et al. 2007). Section 3 presents the theoretical foundation for the design of the new modeling language. It presents a systemic view of strategic sourcing by viewing an enterprise as a service ecosystem focused on value creation. Section 4 presents C.A.R.S as domain-specific strategic sourcing modeling language. Section 5 presents a proof-of-concept $(\mathrm{PoC})$ demonstration and evaluation of a C.A.R.S model-based approach to exploring and evaluating strategic sourcing alternatives by means of a sustainable procurement case-study. Finally, section 6 discusses our contribution and its implications for research and practice and outlines future research. 


\section{Research Methodology}

DSR aims at the scientifically rigorous creation of new artifacts that solve problems relevant to practice and that contribute new knowledge which was acquired through the artifact's development and evaluation process (Hevner et al. 2004). DSR artifacts include constructs, models, methods, instantiations and design theories (Gregor and Hevner 2013). The C.A.R.S modeling language design presented in this paper is a new conceptualization of strategic sourcing according to the value-driven management perspective of Cox (2015) and can be regarded as a model that relates a set of constructs that we propose for describing value co-creation embedded in inter-firm relationships. It thus acts as a new way of modelling to implement the way of thinking of valuedriven strategic sourcing. The language is the conceptual basis for a modelling and analysis approach to explore strategic sourcing alternatives, which provides for a new way of working in strategic sourcing, and can thus be seen as a method artifact. The focus of the paper is on presenting the underlying conceptualization of C.A.R.S (and thus also the theoretical foundation of our solution), whereas the C.A.R.S model-based approach will be illustrated through a case-study which involves an instantiation of the method to the case of sustainable procurement.

Our research process for designing the C.A.R.S conceptualization was guided by the DSR methodology of Peffers et al. (2007) and consists of six steps: (i) Problem identification and motivation through literature review on strategic sourcing; (ii) Definition of solution requirements and research objectives by an analysis of value-driven management in strategic sourcing through the lens of Service Science concepts and theories; (iii) Design and development of a modeling language for systemic exploration of strategic sourcing alternatives; (iv) PoC Demonstration and (v) Evaluation through a case-study; (vi) Scholarly communication within domains such as System Thinking (Rafati and Poels 2017), Service Science (Rafati and Poels 2016) and Strategic Management (Rafati and Poels 2015). Our research methods thus involved literature review, conceptual analysis and design, and application through case-study research.

For reporting the results of our research, we followed guidelines of Gregor and Hevner (2013) and were also inspired by an exemplar DSR study in Service Research (Teixeira et al. 2016). The introduction of this paper reports on steps (i) and (ii), which resulted from our prior research (Rafati and Poels 2016). The theoretical foundation for step (iii) is found in section 3, while the artifact itself is presented in section 4. Steps (iv) and (v) are presented in section 5, where we demonstrate how a C.A.R.S-based modelling approach works by applying it to a real case of sustainable procurement. This application acts as a proof-of-concept of our solution. Referring to the FEDS framework for evaluation in DSR (Venable et al. 2016), the application of our DSR artifact in a case-study is a formative and naturalistic evaluation that fits into a 'human risk \& effectiveness' evaluation strategy. Its aim is to demonstrate how a modelling and analysis approach for exploring strategic souring alternatives based on C.A.R.S can help implementing value-driven management thinking in a real procurement decision-making setting.

\section{Theoretical Foundation - A Service Ecosystem View of Strategic Sourcing}

To address the first research objective, we designed a systemic view of strategic sourcing that is focused on the co-creation of value based on networked relationships. We believe that interpreting complex emerging phenomena such as value co-creation is greatly simplified by a system view that provides a synthesis of on the one hand a reductionist perspective (i.e., analyzing elements and their relationships) and on the other hand a holistic perspective (i.e., the capability of observing the 
whole) (Von Bertalanffy 1972). We propose as systemic view of strategic sourcing a service ecosystem perspective founded on the Viable Systems Approach (vSa) (Polese and Di Nauta 2013) and Service-Dominant Logic (S-D Logic) (Vargo and Akaka 2009). For introducing the ecosystem concept, vSa was selected as it is a descriptive theory of adaptive systems. The S-D Logic is a foundational theory for Service Science that can be used to describe service exchanges. Together they allow to define the concept of service ecosystem.

As a systems theory, $\mathrm{vSa}$ is catching the attention of service researchers as it helps understanding complex phenomena like value co-creation. A viable system is "a system that survives, is both internally and externally balanced, and has mechanisms and opportunities to develop and adapt, and hence to become more and more efficient within its environment" (Beer 1984). We can thus define a service ecosystem as a viable system that is composed of service systems which are internally and externally connected by value co-creation relations that are realized through exchange of service (Vargo and Akaka 2012).

A further foundation for our ecosystem view is S-D Logic. This theory is recognized as the key theoretical foundation for Service Science, which is the discipline that studies service systems (Maglio and Spohrer 2008). In S-D Logic, a service system is defined as a dynamic value cocreation configuration of resources. A service system is related to other service systems by means of value propositions. These value propositions lead to service exchanges between the involved service systems (Vargo and Akaka 2009). Whereas the traditional worldview of strategic sourcing is 'goods-dominant', meaning that sellers and buyers are senders and receivers of goods (which explains the focus on cost savings in the tactical view of procurement), value-driven management fits better the interpretation of value co-creation in terms of actor-to-actor relations as in S-D Logic (Eltantawy et al. 2014). Therefore, a service ecosystem perspective entails a systemic view of strategic sourcing founded on S-D Logic.

To design the envisioned service ecosystem view of strategic sourcing, we mapped S-D Logic concepts onto concepts relevant to strategic sourcing that we derived from three related Strategic Management theories: The Resource-Based View Theory (Barney 1991), the Relational View Theory (Dyer and Singh 1998), and the Dynamic Capability Theory (Helfat et al. 2009) (Table 1). According to the Resource-Based View Theory, only resources that are valuable, rare, inimitable and non-substitutable (VRIN) can provide a sustainable competitive advantage. The Relational View Theory adds to this that strategic sourcing should not only consider firm-level resources and capabilities, but also inter-firm level resources and capabilities based on networked relationships as the source of sustainable competitive advantage. Finally, according to the Dynamic Capability Theory, firms should also have the capability to continuously reconfigure their (VRIN) resource base to sustain their competitive advantage.

Table 1. Mapping of S-D Logic concepts and Strategic Management concepts relevant to strategic sourcing (partly based on (Rafati and Poels 2016))

\begin{tabular}{|l|l|}
\hline \multicolumn{1}{|c|}{ S-D Logic Concepts } & \multicolumn{1}{c|}{ Strategic Management Concepts } \\
\hline $\begin{array}{l}\text { Operand Resources: Tangible, static and passive } \\
\text { resources, like produced goods, money, and } \\
\text { natural resources, that must be acted on to be } \\
\text { beneficial (Vargo and Akaka 2009), (Poels 2010). }\end{array}$ & $\begin{array}{l}\text { Resources: Assets of the firm for which action is } \\
\text { required such that they can help the firm achieve } \\
\text { sustainable competitive advantage. For this to happen, } \\
\text { resources need to be Valuable, Rare, Inimitable, and } \\
\text { Non-substitutable (VRIN) (Barney 1991). Sources of } \\
\text { competitive advantage do not only come from internal } \\
\text { resources (i.e., owned by the firm) but also from } \\
\text { external resources in the value network (Dyer and } \\
\text { Singh 1998). }\end{array}$ \\
\hline
\end{tabular}


Operant Resources: Intangible, dynamic and active resources, like knowledge and skills embodied in persons, that act upon other resources to create benefits (Vargo and Akaka 2009), (Poels 2010). Operant resources are the fundamental source of competitive advantage and differentiation between firms (Lusch et al. 2007).

Service System: A dynamic configuration of resources (including minimally one operant resource) with the capability of providing benefit to other service systems and itself (Vargo and Akaka 2009).

Service: The application of operant resources for the benefit of another party (Vargo and Akaka 2009). Value co-creation is realized through the exchange of service. Competitive advantage is related to how the firm exchanges its services to meet customer needs compared to how other firms exchange their services (Lusch et al. 2007). Service is thus the primary source of competitive advantage.

Actors: Value co-creators that are involved in service exchanges via actor-to-actor (A2A) relations. All actors show the same behavior; they create value for themselves and for others by means of resource integration. An actor on its owns cannot create value for another actor, but can offer a value proposition involving service exchange to realize value co-creation (Vargo and Akaka 2012).

Value: The increase in the viability of the system. Viability can have different meaning depending on the nature of the system (e.g., profitability of profit-seeking firms, well-being of citizens for states). A value proposition leads to the creation of a relation between actors. Co-creating value is a process driven by value-in-use (i.e., value actualization), but mediated and monitored by value-in-exchange (i.e., value capturing) (Vargo and Akaka 2012).
Competencies: Specific strengths of a firm that allow gaining competitive advantage (Hill and Jones 2012). The sources of competitive advantage are not only from the firm-level competencies but also from the inter-firm level competencies (Dyer and Singh 1998).

Capability: A configuration of resources and competencies by which the firm is able to achieve and sustain competitive advantage. Dynamic capabilities refer to the firm's capacities and abilities to reconfigure its resource base internally and externally to achieve sustainable competitive advantage (Helfat et al. 2009). The sources of competitive advantage are not only from internal capabilities but also by leveraging the complementary capabilities of an alliance partner (Dyer and Singh 1998).

Service: Activating competencies in order to achieve competitive advantage. Competitive advantage is observed when a firm creates more economic value than its competitors. This means that the firm's profitability is greater than the average profitability of its competitors. Sustained competitive advantage is observed when a firm maintains an above average and superior profitability for years (Hill and Jones 2012). For profit-seeking firms, the strategic sourcing aims at achieving sustained competitive advantage.

Actors: The players of the firm's value net are able to create joint value that enables firms to compete and cooperate at the same time. In the value net, a customer is a player (actor) that buys the focal firm's products and services. A supplier is a player (actor) that provides resources to the focal firm. A competitor is an alternative player (substitutor) from whom customers may purchase products and services or to whom suppliers may sell their resources. A complementor is a player from whom customers buy complementary products and services or to whom suppliers sell complementary resources. All players (actors) bring their own (added) value to the firm network to create a total value (Brandenburger and Nalebuff 2011). Therefore, in a value net, the role of each player (actor) is that of value co-creator.

Perceived value: The usefulness of the offered product as perceived by customers. Exchange value is realized at the moment of selling the product, being the amount paid by the buyer to the seller as valuation for perceived value (Bowman and Ambrosini 2000). Every value net has a total value, which is the sum of the added values of each player in the value net. Added value is what each player (actor) brings to the firm network to create a total value (Brandenburger and Nalebuff 2011). 
Given this mapping, we define strategic sourcing from a service ecosystem perspective as $a$ strategic process for organizing and fine-tuning the focal firm's resources, competencies and capabilities internally and externally through actor-to-actor interactions with its value net's players (e.g., suppliers, internal and external customers, competitors and complementors) for joint value creation in order to achieve (sustainable) competitive advantage.

\section{Artifact Description - The C.A.R.S Modeling Language}

The second research objective involved the design of a modeling language for exploring strategic sourcing alternatives. This design is based on the theoretical foundation in the form of the systemic view of value-driven strategic sourcing that was presented in the previous section.

C.A.R.S is a new language for strategic sourcing modeling (Fig. 2). The modeling concepts (and their relationships) of C.A.R.S are directly derived from S-D Logic concepts as they were mapped onto the concepts relevant to strategic sourcing (see table 1). C.A.R.S consists of the following concepts:

Capability. A capability describes what an actor can do to ensure competitiveness. More specifically, a capability is the capacity and ability of an actor to co-create value through service exchanges. In this context, a capability can be considered as the result of a specific configuration of resources (i.e., a service system in S-D Logic), which need to be sourced. Moreover, the capability notion refers both to internal capabilities of the firm and the complementary capabilities of partners within the value net. A capability has potentially a long-term effect on the achievement of strategic objectives. Therefore, value-driven Key Performance Indicators (KPIs) (e.g., KPIs for documentation and self-audit, quality management, and design and development) can be defined based on the capabilities of actors in the value net. These KPIs are related to functional abilities like the organizational, managerial, and technical ability to measure long-term effects in achieving strategic goals such as establishing long-term partnerships or developing a sustainable competitive advantage (Ellram 1990).

Actor. An actor is seen a resource integrator that provides services and co-creates value. This actor notion is used to describe the role of players in the focal firm's value net. Within this network, all players (actors) bring their own value (added value) to create a total value. Hence, the role of each player (as actor) is that of value co-creator.

Resource. The resource base describes what an actor has, which can be configured to exchange services and to support the creation of value. The resource notion refers both to the internal resources owned by the firm and the external (inter-firm level) resources within the firm's value net. As such, the resource base is composed of static resources, usually tangible (e.g., goods), and dynamic resources, usually intangible (e.g., skills and competencies). Figure 2 makes a distinction between assets and competencies, respectively the operand and operant resources in S-D Logic.

Service. A service is the application of resources by an actor. Services can be exchanged with other actors to create value and to ensure organizational competitiveness. We use this notion in C.A.R.S to capture the performance of actors in achieving sourcing objectives. Cost-down KPIs can be defined for strategic sourcing, based on actor performance in service exchanges. Such cost-saving KPIs are quantifiable performance metrics to measure short-term effects in achieving strategic 
goals. Examples of these metrics are the cost of a service, the quality of a service, the delivery time of a service, etc. (Ellram 1990).

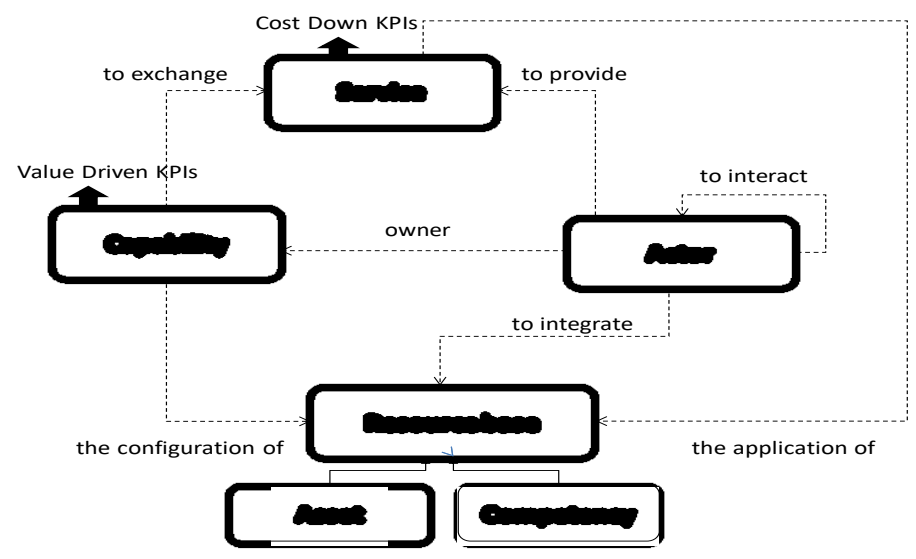

Fig. 2. C.A.R.S modeling concepts

\section{Application - A Case-Study of Value-Driven Strategic Sourcing}

We first describe the case-study company and its approach to strategic sourcing. Next, we present our case-study intervention demonstrating the use of C.A.R.S. Afterwards we evaluate our intervention as a proof-of-concept for our proposed solution.

\subsection{Sustainable Procurement at Umicore}

Umicore is a multinational materials technology and recycling company headquartered in Brussels, Belgium. The company generates the majority of its revenues based on clean technologies such as recycling, emission control catalysts, and materials for rechargeable batteries. Umicore defines its vision on sustainable value creation as to develop, produce and recycle materials in a way that fulfills its mission which is "materials for a better life"

The group has two functions for purchasing: direct procurement and indirect procurement. Direct procurement refers to sourcing of third party services and goods that are part of, or used in manufacturing and production. Indirect procurement refers to sourcing of categories of goods and services that are supporting organizational processes. For indirect procurement, the current approach can be characterized as tactical spend management. The main aim is to develop costeffective sourcing strategies based on performance metrics like cost, quality and geographical location. Direct procurement, on the other hand, is clearly a value-driven process with ecological, social and economic sustainable value creation as pervasive value that drives all procurement decisions and activities. Sustainable procurement translates into goals of establishing long-lasting partnerships with suppliers, co-developing sustainable products and services, and tracking and reporting supplier performance based on sustainability metrics.

To operationalize its sustainable procurement goals, Umicore has set up a sustainable procurement charter for requesting all its suppliers to act more sustainably. The charter puts forward a number of principles in the fields of environment, labor practices and human rights, business integrity, and the supply chain of the suppliers. According to the annual report of Umicore's economic, social and environmental performance in 2015, Umicore's procurement 
teams first selected key suppliers of goods, services and raw materials based on criteria such as size, geographical location and the criticality of provided services and products. After this primary selection, 1,336 suppliers were invited to conform to the charter and 1,108 (83\%) of these 1,336 suppliers replied that they could meet the terms of the charter. Umicore's procurement teams further identified 47 suppliers out of the 1,108 suppliers based on a risk assessment using operational metrics like critical dependency, geographical presence and spend costs. These suppliers were referred to EcoVadis, which is an independent sustainability-rating service provider, for an evaluation of their corporate social responsibility (CSR). EcoVadis provides sustainability ratings and a performance improvement tool for global supply chains by delivering scorecards to monitor supplier practices covering 150 purchase categories, 110 countries and 21 CSR indicators. EcoVadis assessed the sustainability performance of 40 suppliers by providing an overall score and a score for each of four sustainability categories: environment, labor practices, fair business practices and sustainable procurement. According to the result of this assessment, 22 companies have the score between 25 and 44, meaning that they are following basic steps to ensure sustainability. Among these companies, one company has the score of 20, representing a high risk in sustainability. Another 14 companies scored between 45 and 64, meaning that they have an appropriate sustainability management system, while 3 companies have higher scores than 64, showing that they have the most advanced practices on sustainability.

\subsection{Application of C.A.R.S at Umicore}

For direct procurement, Umicore's approach of sustainable procurement can be characterized as value-driven strategic sourcing. Umicore sustainable procurement focuses on value creation through three value drivers (i) cost reduction (e.g., energy cost, social cost and environmental taxes); (ii) risk mitigation (e.g., supply chain disruptions, brand damage from bad supplier practice); and (iii) revenue/growth generation (e.g., income from recycling and innovations in sustainable development). Sustainable procurement as value-driven strategic sourcing is defined as an annual project at Umicore. This project includes four phases: (1) inviting suppliers to adhere to the sustainable procurement charter after a primary selection based on performance metrics like size, geographical location and the critically of provided services and products; (2) providing suppliers that are willing to adhere to the sustainable procurement charter with a self-assessment questionnaire according to the charter principles; (3) selecting suppliers for CSR evaluation amongst those suppliers that returned the questionnaire, based on a risk assessment using operational metrics; and (4) evaluating supplier sustainability performance based on the CSR scorecards provided by EcoVadis.

Despite these efforts and intentions, we learned through an interview we had with our case-study partner, the director of the Umicore Brussels' regional procurement center, that sustainable procurement is not a systemic and integrated process at Umicore. Specific problems mentioned were (1) Applying the sustainable procurement selection as an annual project for the entire supply chain instead of exploring whenever needed sourcing alternatives for a specific service or supplier; (2) The use of operational performance metrics and self-assessment questions for supplier selection and evaluation that do not match well Umicore's long-term sustainability objectives; and (3) The use of generic CSR metrics that are defined for use in 25,000 companies in 110 countries, but that were not specifically defined for Umicore.

In the remainder of this section, we illustrate how a chief procurement officer (CPO) at Umicore can apply a model-based approach using C.A.R.S as a systemic, integrated and value-driven approach to explore strategies and recommendations in line with sustainable procurement at 
Umicore, hence addressing the aforementioned problems. Through this illustration, we also explain the different steps of the C.A.R.S modeling method with a focus on value-driven strategic sourcing of capabilities, i.e., choosing the right capability sourcing alternatives and right partners. The effective sourcing of capabilities, which are used to exchange services, is crucial to achieve competitiveness for an organization across the value chain and within a changing environment.

The C.A.R.S modeling method has four steps: (i) Conduct a value net analysis; (ii) Determine the capability positioning; (iii) Determine the dependency positioning; and (iv) Identify capability sourcing options (see figure 3). We discussed with the director of Brussels' procurement center a sourcing scenario at Umicore in line with sustainable procurement. Using this scenario, we can demonstrate the C.A.R.S model-based exploration of strategic sourcing options. This sourcing scenario is based on the existing collaboration between Umicore as a materials technology leader and Prayon as a phosphate producer to jointly develop and produce phosphate-based cathode materials for use in rechargeable batteries. All models developed were based on information made available by Umicore (often freely available) and discussed with our case-study partner.

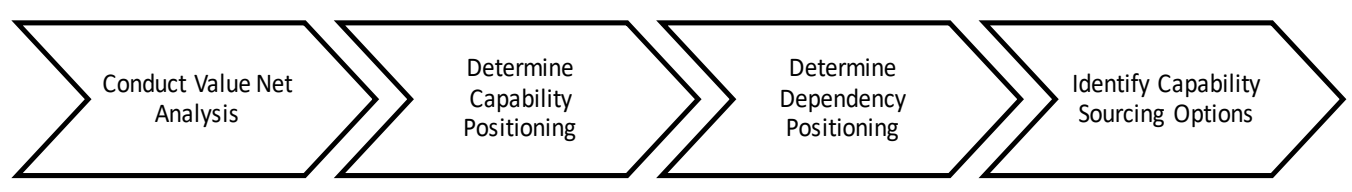

Fig. 3. C.A.R.S modeling steps

Step 1: Conduct Value Net Analysis. The first step aims to increase the understanding of the value net to better assess opportunities for strategic sourcing. Our approach analyzes the value net by considering the required capabilities for value creation in order to achieve sustainability objectives. Figure 4 shows the value net profile model for the selected sourcing scenario. This model is a C.A.R.S model instantiation which shows that the development of a new sustainable product (i.e., phosphate-based cathode materials for use in rechargeable batteries) is a service that is able to deliver value which will result in a sustainable competitive advantage in the materials industry. The associated value of this new service is increasing growth in the materials market by offering a new type of cathode materials for use in new energy solutions for the automotive sector (e.g., hybrid, micro-hybrid and electric vehicles) and for enabling new applications such as stationary applications (e.g., solar and wind power storage systems). The total value co-created by participation of Umicore and Prayon is an aggregation of economic value (i.e., a high quality and cost-competitive product), environmental value (i.e., an environmentally friendly or eco-friendly product) and social value (i.e., occupational health and safety at workplaces and sites). For 'exchanging' this new service, meaning for developing the phosphate-based cathode materials, two core capabilities are required: (i) An internal capability possessed by Umicore (i.e., developing cathode materials); and (ii) A complementary capability possessed by Prayon (i.e., developing phosphate materials). Both capabilities are configurations of internal and external resources (i.e., assets, competencies, skills, systems, standards, technologies). Furthermore, the resource base includes specific programs, competencies, systems, standards and practices for sustainability. If the capability of an actor involves such sustainability resources, then the actor has the potential to play sustainably in the value net.

According to our value net analysis based on the developed value net profile model, both the developing of phosphate materials and cathode materials, which are technical capabilities of respectively Prayon and Umicore, are defined as configurations of resources including 
sustainability resources like green infrastructures, green raw materials, sustainable development programs and plans (e.g., Horizon 2020, UN Agenda 2030), sustainable standards and principles (e.g., sustainable procurement charter), sustainable practices, and environmental management systems for prevention and controlling pollution. Hence, Prayon and Umicore are both able to act as sustainable players in the value net.

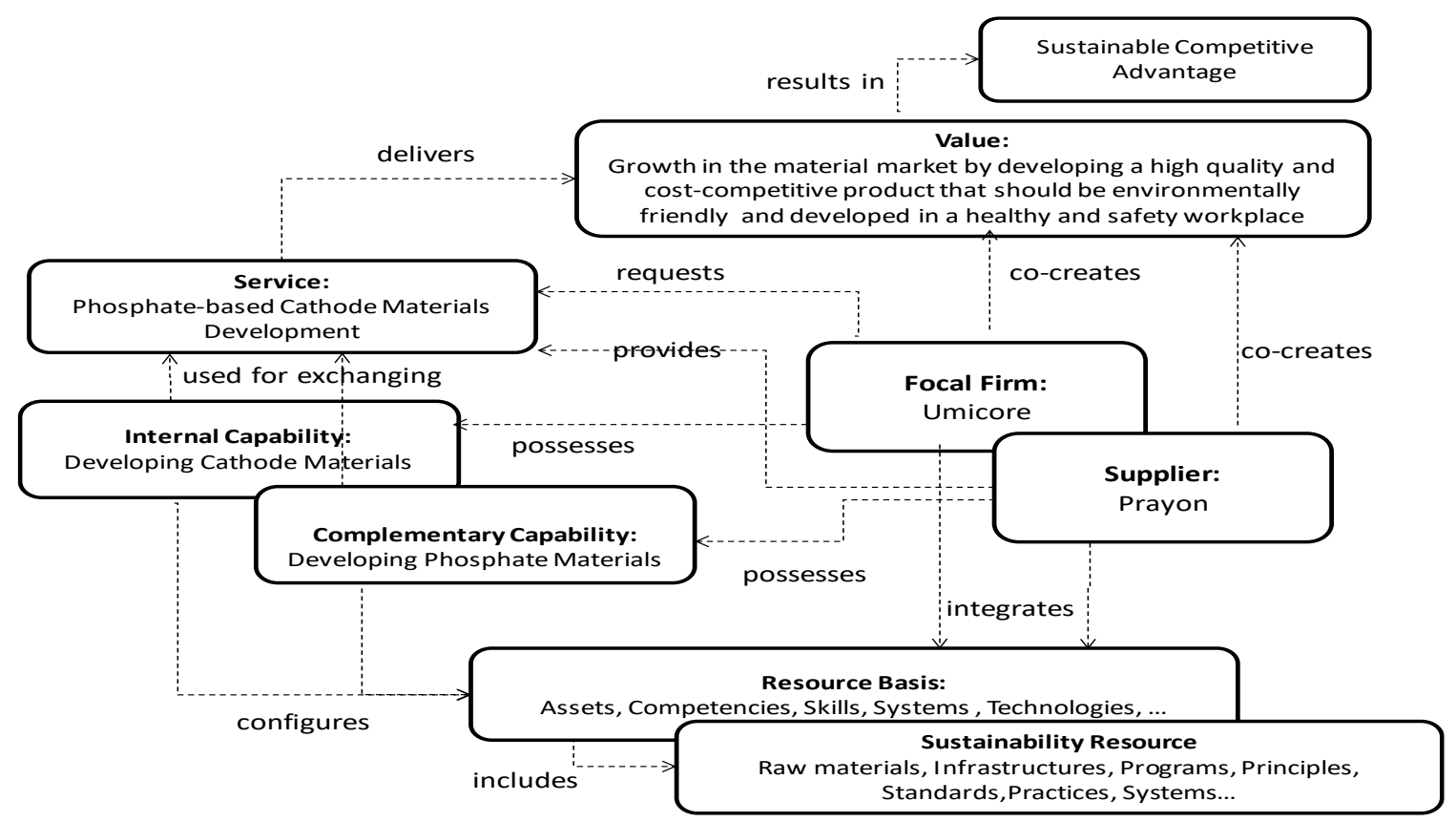

Fig. 4. The value net profile of Umicore for the target service

Step 2: Determine Capability Positioning: This second step aims to position the capabilities of the players in the value net to evaluate their strategic and sustainability impacts. Following Cox's idea of criticality analysis (Cox 2015), we introduce the capability positioning portfolio focusing on the C.A.R.S capability and resource concepts. Two capability dimensions are used for positioning: (i) The strategic impact measured by a VRIN assessment of the available resource base to achieve the desired outcome, i.e., assessing whether the required resources are valuable, rare, inimitable, and non-substitutable; (ii) the sustainability impact measured by economic factors (e.g., cost, quality and delivery time), social factors (e.g., customer privacy, health and safety of staff and customer, satisfactory working environments and discrimination in employment), and environmental factors (e.g., resource consumption, recycling income, environmental taxes). This results in a 2 x 2 matrix as capability positioning portfolio model with four capability categories: (i) strategic sustainability capability, (ii) sustainability capability, (iii) strategic non-sustainability capability, and (iv) nonsustainability capability. The capability positioning portfolio model of Umicore (see figure 5) shows that the phosphate-based cathode materials developing capability, which combines the internal capability of Umicore (i.e., developing cathode materials) and the complementary capability of Prayon (i.e., developing phosphate material), is a configuration of VRIN resources with a high-level sustainability impact, hence can be positioned as a strategic sustainability capability that is able to achieve sustainable competitive advantage in the material market. 


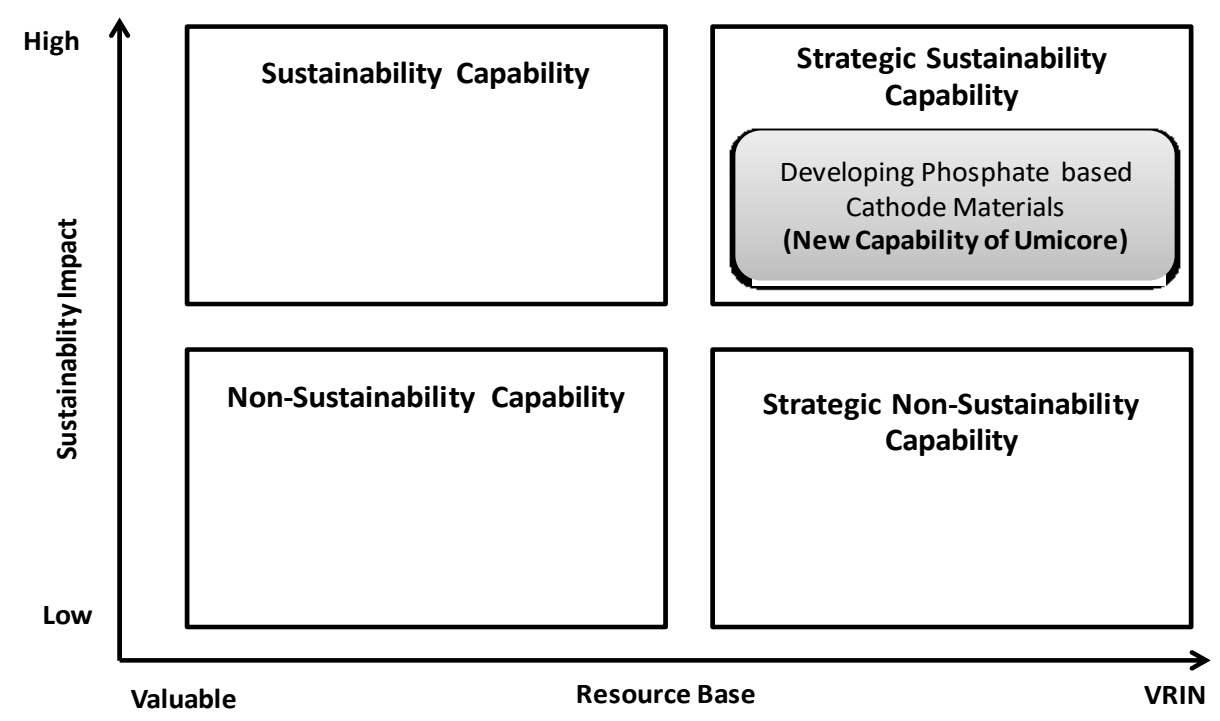

Fig. 5. The capability positioning portfolio of Umicore for a specific capability

Step 3: Determine Dependency Positioning: The purpose of the third step is to position the mutual dependency between buyers and suppliers to shape relationship strategies in the value net. Inspired by Cox's power portfolio model (Cox, 2001), the dependency positioning model is a C.A.R.S model instantiation that is used to classify a buyer-supplier dependency into one of four possible categories (i) buyer dominance (buyer has more power than supplier), (ii) supplier dominance (supplier has more power than buyer), (iii) interdependence (high balanced power) and (iv) independence (low balanced power). The power of both parties is measured by (i) the essentiality of the exchanged service (Jacobs, 1974) and (ii) the critically of the capability to exchange services. Applied to our case, the essentiality of a service is determined by the relative financial, environmental and social impact of the service for value creation to achieve sustainability objectives. The critically of the capability to exchange services is determined by its resource base. The buyer-supplier dependency analysis (see figure 6) shows that the phosphate-based cathode materials development service is an essential service for both Umicore and Prayon with high-level financial, economic and environmental impacts which were measured by the metrics mentioned in the previous step. For both players, this essential service is exchanged by employing complementary strategic sustainability capabilities, which are developing cathode materials from Umicore's side and phosphate material developing from Prayon's side. As shown in the previous step, both contributing capabilities are based on a VRIN sustainability resource base. Based on our analysis, the relationship between Umicore and Prayon can be positioned as an "interdependence" relationship. 


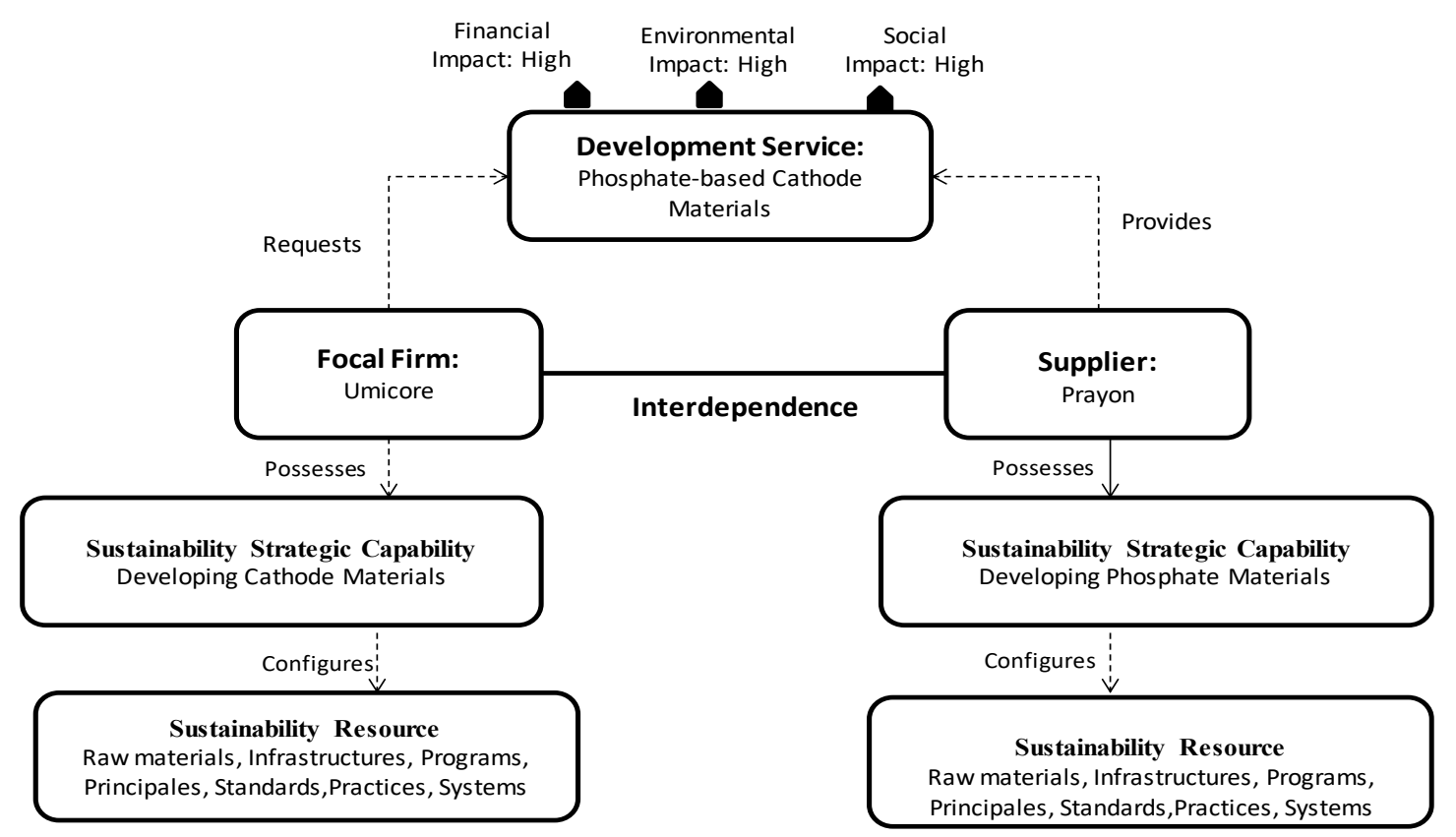

Fig. 6. Dependency positioning model of Umicore and Prayon

Step 4: Identify capability sourcing strategies: The goal of the last step in the modeling method is to develop a capability sourcing portfolio analysis model for classifying and setting capability sourcing strategies. The proposed model uses a 4 x 4 matrix to classify 16 capability sourcing categories. This classification is performed based on the results of the capability positioning (step 2) and the buyer-supplier dependency positioning (step 3). Capability sourcing portfolio analysis is inspired by the sourcing portfolio analysis of Cox (2015), which determines supply strategies based on two leveraging principles for exploring sourcing options: (i) Firms can move into supply markets with low complexity; and (ii) firms obtain an understanding of their current position and search for ways to exploit or balance existing relationships. 


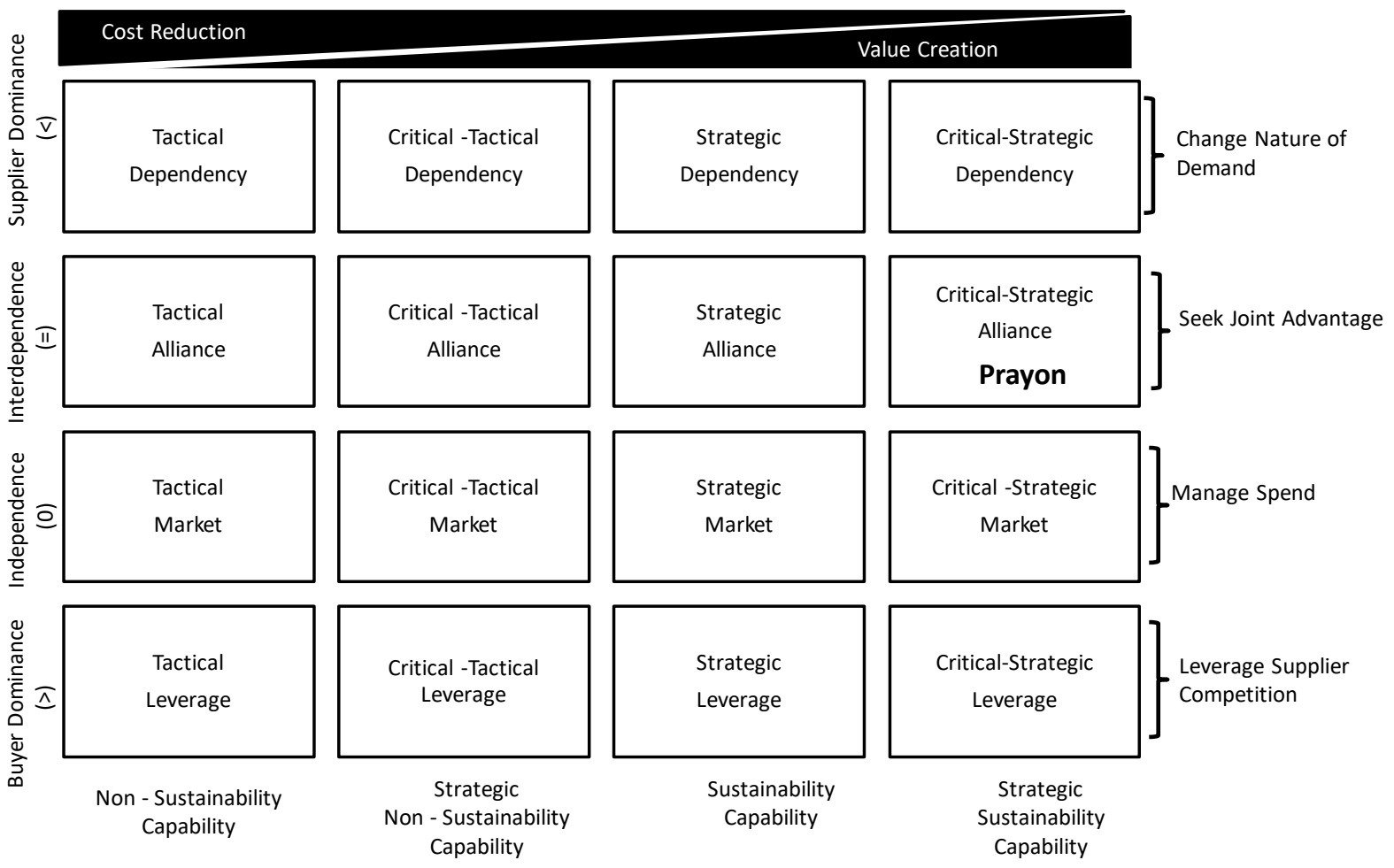

Fig.7. Capability sourcing portfolio analysis model as applied to the Prayon supplier

According to the previous analyses, Prayon is positioned into the Critical-Strategic Alliance cell of the model. Consequently, the possible strategies and options for Umicore for sourcing phosphate based cathode materials development as a strategic sustainability capability are:

- Stay in an alliance position with Prayon and establish a long-term strategic relationship by use of profit sharing and strategic alliance. A possible disadvantage of this option is the emergence of a lock-in partnership.

- Move to the leverage position (i.e., Critical-Strategic Leverage cell) and exploit Umicore's buying power through market competition and short-term agreements among available chemical companies in the market. However, this can have a negative impact on the creation of value. In general, for implementation of this strategy, the possible sourcing approaches are (i) Tendering by use of RFI/RFP processes; (ii) Globalization by global sourcing and low-cost country sourcing; (iii) Supplier pricing review by total cost of ownership; and (iv) Target pricing by cost regression analysis. It is clear that approaches (ii), (iii) and (iv) will not contribute to achieving sustainability objectives, while it is unsure that approach (i) will lead to the identification of a valuable alternative to Prayon, meaning with a similar complementary strategic sustainability capability.

\subsection{Evaluation}

With respect to the identified problems of current sustainable procurement practice at Umicore, our approach can be used as an ongoing process not only for supplier selection and evaluation but also for exploring sourcing alternatives related to a specific service or supplier (first problem). The proposed modeling approach measures the sustainability of value net players by considering both their performance and capability dimensions (second problem). In the case study, the C.A.R.S 
modeling method evaluated the sustainability performance of Prayon based on operational economic, social and environmental metrics like cost, recycling income and customer privacy. But in addition, the strategic sustainability of Prayon's developing phosphate materials capability was also determined based on its VRIN resources with high-level sustainability impact. Finally, the C.A.R.S modeling approach evaluates the sustainability of value net players according to the specific economic, social and environmental factors appropriate to a specific service in a business line (third problem). In the case study, the sustainability impact of Umicore and Prayon's joint phosphate-based cathode materials developing capability was evaluated based on relevant economic, social and environmental factors, which were specifically defined for the energy materials critical business line at Umicore.

\section{Discussion, Conclusion and Future Research}

To address the solution requirements (see section 1) for realizing value-driven strategic sourcing, we introduced C.A.R.S as a systemic and integrated modeling approach that provides a holistic view on the firm's value network (Req.1) emphasizing value co-creation (Req.2) by considering inter-firm interactions (Req.3). The proposed modeling approach supports CPOs in exploring strategic sourcing alternatives (Req.4) to achieve strategic goals. This was demonstrated in a casestudy of sustainable procurement at Umicore, in which model-based analysis using C.A.R.S was applied to analyze a partnership with Prayon to develop phosphate-based cathode materials for rechargeable batteries. The analysis confirmed the strategic alliance with Prayon and identified an alternative (but probably less optimal) strategic sourcing alternative.

Referring to the DSR knowledge contribution framework of Gregor and Hevner (2013), the type of knowledge contribution we make with C.A.R.S is exaptation, where known solutions are extended to new problems. Value-driven management is a true innovation in strategic sourcing. Our solution uses knowledge from Service Science and Conceptual Modeling to address the problem of lack of instruments to implement value-driven management in strategic sourcing. We did so by designing a conceptual modelling language which was founded on a systemic view of strategic sourcing that was derived from a mapping of Service Science concepts to Strategic Management concepts. Again, referring to Gregor and Hevner (2013), the instantiation of the C.A.R.S-based modelling approach to the particular case-study at Umicore can be seen as a level 1 knowledge contribution type ('situated implementation of artifact'), whereas the C.A.R.S conceptualization itself is of level 2 ('nascent design theory'). The implication for research is the knowledge incorporated in the design of C.A.R.S, which provides a basis for further research into how conceptual modeling and service ecosystems thinking helps implementing value-driven strategic sourcing. The implication for practice is the development of a practical approach to implement value-driven strategic sourcing, which also requires further research as will be detailed next.

Our research is not without limitations. First, as C.A.R.S was only applied to one sourcing scenario and was not division-wide or company-wide implemented within Umicore, we have not provided evidence of its efficacy but only showed its potential in solving specific procurement problems related to sustainable procurement at Umicore. Second, although the case-study enabled us to demonstrate the potential utility of the C.A.R.S approach, we acknowledge that it is difficult to generalize the results based on a single case study in a specific setting (i.e., sustainable procurement as value-driven strategic sourcing). Third, as our approach is work-in-progress and currently lacks software tools to support the modeling and analysis tasks, the case-study involved 
the active participation of the researchers and required extensive documentation on behalf of the case study organization. These limitations of the research need to be addressed by our future research.

In previous research, we have applied a preliminary version of the approach to an IT outsourcing case-study in a large hospital (Rafati and Poels 2016). Further case-studies are needed to explore the support for value-driven strategic sourcing in different domains (e.g., contracting services from public authorities), for different sourcing scenarios (e.g., actors being simultaneously buyer and supplier in a value co-creation process), for different sourcing trends (e.g., business process outsourcing, offshoring and global sourcing), and in different sourcing contexts (e.g., emerging economies, instable regulatory environments). This research can potentially result in adaptations to the modeling approach. It will also inform us on the boundaries of the application scope of C.A.R.S. We acknowledge that defining this application scope explicitly, e.g., through an axiomatization that emphasizes specific properties of C.A.R.S concepts depending on the application context, is a major research challenge and might require other research that extends the current case-study research.

Our future research plans also include the development of techniques to enable a more rigorous analysis of strategic sourcing options (e.g., using heuristic methods), which we identified as a main challenge in this field. Future research may, for instance, look into how to incorporate in the analysis sourcing strategies that allow recovering from disturbing or disruptive events which affect the sourcing of capabilities and the performance of value co-creation processes. Another future research idea is to strengthen the rigor of the analysis by means of game theoretic models, for instance by associating to the capability sourcing portfolio model a bi-matrix game model for which Nash equilibria can be calculated. Our immediate next research steps will be focused on the development of a more formal meta-model, semantics and a concrete syntax, views and models for C.A.R.S and a supporting modeling method and tools for value-driven strategic sourcing with C.A.R.S. Specifically needed are easy-to-use tools for model-based analysis of strategic sourcing alternatives that allow working with the different modeling, positioning and analysis techniques that were illustrated in this paper.

\section{Acknowledgements}

The research reported in this paper was performed as part of research project G081412N financed by the Foundation for Scientific Research - Flanders.

\section{References}

Anderson PH, Rask M (2003) Supply chain management: new organizational practices for changing procurement realities. Journal of Purchasing and Supply Management. 9(2): 83-95.

Barney JB (1991) Firm resources and sustained competitive advantage. Journal of Management. 17 (1): $99-120$.

Beer S (1984) The viable system model: Its provenance, development, methodology and pathology. Journal of the operational research society. 35(1): 7-25.

Bowman C, Ambrosini V (2000) Value Creation versus Value Capture: Towards a Coherent Definition of Value in Strategy. British Journal of Management, Vol. 11, pp.1-15. 
Brandenburger AM, Nalebuff BJ (2011) Co-opetition. Crown Business.

Cardoso J, Lopes R, Poels G (2014) Service systems: concepts, modeling, and programming. Springer, pp. 1-91.

Chen IJ, Paulraj A, Lado A (2004) Strategic purchasing, supply management and firm performance. Journal of Operations Management. 22 (5): 505-523.

Cox A (2001) Understanding Buyer and Supplier Power: A Framework for Procurement and Supply Competence. The Journal of Supply Chain Management. 37 (1): 8-15.

Cox A (2015) Sourcing portfolio analysis and power positioning: towards a "paradigm shift" in category management and strategic sourcing. Supply Chain Management: An International Journal. 20(6): 717-736.

Cox A, Ireland P (2015) Value Sourcing: From Spend Management to Supply Management, Kindle E-Book, Earlsgate Press, Stratford-upon-Avon.

Dyer JH, Singh H (1998) The relational view: Cooperative strategy and sources of interorganizational competitive advantage. Academy of management review. 23(4): 660-679.

Ellram LM (1990) The supplier selection decision in strategic partnerships. Journal of Purchasing and materials Management, 26(4), 8-14.

Eltantawy R, Giunipero L, Handfield R (2014) Strategic Sourcing Management's Mindset: Strategic Sourcing Orientation and its Implications. International Journal of Physical Distribution and Logistics Management. 44(10): 768-795.

Gregor S, Hevner AR (2013) Positioning and presenting design science research for maximum impact. MIS Quarterly. 37(2): 337-355.

Helfat C, Finkelstein S, Mitchell W, Peteraf M, Singh H, Teece D, Winter S (2009) Dynamic Capabilities: Understanding Strategic Change in Organizations. John Wiley \& Sons.

Hevner R, March ST, Park J, Ram S (2004) Design science in information systems research. MIS quarterly. 28(1): 75105.

Hill C, Jones G (2012) Strategic Management: an integrated approach. Tenth edition, Cengage Learning.

Jacobs J (1974) Dependency and vulnerability: An exchange approach to the control of organizations. Administrative Sciences Quarterly. 19(1): 45-59.

Kocabasoglu C, Suresh NC (2006) Strategic sourcing : an empirical investigation of the concept and its practices in US manufacturing firms. Journal of Supply Chain Management. 42(2): 4-16.

Kraljic P (1983) Purchasing must become supply management. Harvard Business Review. 61 (5): $109-117$.

Lusch RF, Stephen L, Vargo SL, Matthew O (2007) Competing through service: Insights from service-dominant logic. Journal of Retailing. 83(1): 2-18.

Lusch RF, Vargo SL (2006) Service-dominant logic: reactions, reflections and refinements. Marketing theory. 6(3): 281-288.

Maglio PP, Spohrer J (2008) Fundamentals of service science. Journal of the Academy of Marketing Science. 36(1): $18-20$. 
Osterwalder A, Pigneur, Y (2012) Designing Business Models and Similar Strategic Objects: The Contribution of IS. Journal of the Association for Information Systems, 14(5), 3.

Peffers K, Tuunanen T, Rothenberger MA, Chatterjee S (2007) A design science research methodology for information systems research. Journal of Management Information Systems. 24(3): 45-77.

Poels G (2010) The resource-service-system model for service science. International conference on Advances in conceptual modeling: applications and challenges. Springer Berlin Heidelberg. 6413. pp.117-126.

Polese F, Di Nauta P (2013) A viable systems approach to relationship management in SD logic and service science. in Business Administration Review. Schäffer-Poeschel. 73(2): 113-129.

Rafati L, Poels G (2017) Service Oriented Enterprise Engineering: A modeling discipline based on the viable system approach (vSa) for strategic sourcing decision-making. special issue of the International Journal of Information Systems in the Service Sector (IJISSS). Conditionally accepted for publication.

Rafati L, Poels G (2016) Service-Dominant Strategic Sourcing: Value Creation Versus Cost Saving. Exploring Services Science. Volume 247 of the series Lecture Notes in Business Information Processing. pp 30-44.

Rafati, L., \& Poels, G. (2015) Towards Model-Based Strategic Sourcing. In Achieving Success and Innovation in Global Sourcing: Perspectives and Practices. Springer International Publishing. pp. 29-51.

Schuh C, Kromoser R, Strohmer MF, Pérez RR, Triplat A (2009) The Purchasing Chessboard ${ }^{\mathrm{TM}}$, pp. 55-207, Springer Berlin Heidelberg.

Spohrer J, Barile S, Polese F (2010) System Thinking for Service Research Advances. Service Science. 1(2): 130-135.

Teixeira JG, Patricio L, Huang K-H, Fisk RP, Nóbrega L, Constantine L (2016) The MINDS method: Integrating Management and Interaction Design Perspectives for Service Design. Journal of Service Research. DOI: $10.1177 / 1094670516680033$.

Thalheim B (2012) The science and art of conceptual modelling. In Transactions on Large-Scale Data-and KnowledgeCentered Systems VI (pp. 76-105). Springer Berlin Heidelberg.

Van Weele AJ (2009) Purchasing and supply chain management: Analysis, strategy, planning and practice. Cengage Learning EMEA.

Vargo SL, Akaka MA (2009) Service-dominant logic as a foundation for service science: clarifications. Service Science. 1(1): 32-41.

Vargo SL, Akaka MA (2012) Value Co-creation and Service Systems (Re)formation: A Service Ecosystems View. Service Science. 4(3): 207-217.

Venable J, Pries-Heje J, Baskerville S (2016) FEDS: A framework for evaluation in design science research. European Journal of Information Systems. 25: 77-89.

Von Bertalanffy L (1972) The history and status of general systems theory. Academy of Management Journal, 15(4): 407-426. 